\title{
Combustion characteristics of water-insoluble elemental and organic carbon in size selected ambient aerosol particles
}

\author{
K. Wittmaack \\ GSF - National Research Centre for Environment and Health, Institute of Radiation Protection, 85758 Neuherberg, Germany
}

Received: 1 March 2005 - Published in Atmos. Chem. Phys. Discuss.: 13 April 2005

Revised: 28 June 2005 - Accepted: 28 June 2005 - Published: 27 July 2005

\begin{abstract}
Combustion of elemental carbon (EC) and organic carbon (OC) contained in ambient aerosol matter was explored using scanning electron microscopy (SEM) in combination with energy dispersive X-ray analysis (EDX). To ease identification of the particles of interest and to avoid or at least reduce interaction with simultaneously sampled inorganic oxides and salts, the approach used in this work differed in two ways from commonly applied procedures. First, rather than using a mixture of particles of vastly different sizes, as in PM10 or PM2.5, aerosol matter was collected in a 5-stage impactor. Second, the water soluble fraction of the collected matter was removed prior to analysis. Diesel soot particles, which appeared in the well-known form of chaintype aggregates, constituted the major fraction of EC. In contrast, OC containing particles were observed in a variety of shapes, including a sizable amount of bioaerosol matter appearing mostly in the size range above about $1 \mu \mathrm{m}$. During heating in ambient air for $1 \mathrm{~h}$, diesel soot particles were found to be stable up to $470^{\circ} \mathrm{C}$, but complete combustion occurred in a narrow temperature interval between about 480 and $510^{\circ} \mathrm{C}$. After diesel soot combustion, minute quantities of "ash" were observed in the form of aggregated tiny particles with sizes less than $10 \mathrm{~nm}$. These particles could be due to elemental or oxidic contaminants of diesel soot. Combustion of OC was observed over a wide range of temperatures, from well below $200^{\circ} \mathrm{C}$ to at least $500^{\circ} \mathrm{C}$. Incompletely burnt bioaerosol matter was still found after heating to $600^{\circ} \mathrm{C}$. The results imply that the EC fraction in aerosol matter can be overestimated significantly if the contribution of OC to a thermogram is not well separated.
\end{abstract}

Correspondence to: $\mathrm{K}$. Wittmaack

(wittmaack@gsf.de)

\section{Introduction}

Carbonaceous particles constitute a significant if not a large fraction of atmospheric aerosol matter (Molnár et al., 1999; Putaud et al., 2004; ten Brink et al., 2004). It is common practice to distinguish two categories, organic carbon (OC) and elemental carbon (EC). Quantitative measurements of $\mathrm{OC}$ and EC are hampered by sometimes severe sampling artefacts (Kirchstetter et al., 2001; Mader at al., 2003; ten Brink et al., 2004) as well as by the fact that analytical methods based on the use of fundamental properties are not available. The mass of OC and EC in a given sample is usually determined by combustion, applying certain protocols which define the temperature and duration of heating, the composition of the gas atmosphere, the method of analysing gaseous carbon evolving from the sample, the control of sample charring etc. Depending on the details of the protocols, the results for EC were found to differ significantly (Hitzenberger et al., 1999; Schmid et al., 2001; ten Brink et al., 2004), in extreme cases by as much as a factor of 12 (Schmid et al., 2001). Part of the problem relates to the fact that OC comprises a diverse mixture of materials ranging from small organic molecules to bioaerosols (Cachier, 1998). These various components of OC exhibit different characteristic temperatures of desorption, pyrolysis and combustion. EC containing particles, on the other hand, may be expected to feature a comparatively well defined combustion behaviour. Preliminary evidence in this respect was recently obtained using scanning electron microscopy (SEM) to trace the incineration of diesel soot carbon nanoparticles after different steps of $1 \mathrm{~h}$ heating in ambient air (Wittmaack, 2004). The diesel particles, which are known to be composed of EC in the form of graphitic crystallites (Ishiguro et al., 1997; Wentzel et al., 2003), remained essentially unchanged after heating to $400^{\circ} \mathrm{C}$, but had disappeared completely after heating to $500^{\circ} \mathrm{C}$. 
The purpose of this study was to extend the previous work with the aim of arriving at a detailed picture of the combustion characteristics of a variety of OC containing particles as well as of diesel soot, the latter often comprising the largest fraction of EC particulate matter. The results of such an investigation might help to interpret the different peaks routinely observed in thermograms of ambient aerosol matter at temperatures between 100 and $850^{\circ} \mathrm{C}$ (Chow et al., 2001). A detailed peak assignment has not been possible in previous work.

The approach explored here differs in several ways from commonly used procedures for determining $\mathrm{EC}$ and $\mathrm{OC}$ in ambient aerosol matter. The standard approach is collect particles with aerodynamic diameters less than 10 or $2.5 \mu \mathrm{m}$ (PM10 or PM2.5, respectively) on quartz fibre filters (Hitzenberger et al., 1999; Schmid et al., 2001; Mader et al., 2003; ten Brink et al., 2004) and to determine the combustion characteristics of the as-sampled aerosol matter, with or without determining the changes in optical transmission or reflectance during the heating procedure (Cachier, 1998; Chow et al., 2001). EC and OC measurements on size fractionated aerosols collected in impactors are rare (Maenhaut et al., 2002). To the author's knowledge, a detailed comparison of the thermograms observed in different size ranges has only been reported once (Novakov et al., 2000).

The other difference to previous studies is that in this work the water soluble aerosol matter was extracted prior to analysis and heat treatment. The procedure, tested (Wittmaack et al., 2002) and applied before (Wittmaack, 2004), has several advantages. First, many OC and EC containing particles, which may be covered by inorganic matter after prolonged sampling, become visible in SEM analysis. Second, combustion artefacts due to interaction with inorganic matter (Chow et al., 2001) are removed or at least reduced. Related analyses on PM2.5 samples performed in the author's laboratory by proton induced X-ray emission (PIXE), before and after soluble-matter extraction with water, revealed large to high solubility, not only for critical alkali elements (Novakov and Corrigan, 1995) like $\mathrm{Na}(\sim 90 \%)$ and $\mathrm{K}(\sim 60 \%)$ but also for transition elements like $\mathrm{Zn}(\sim 80 \%)$ and $\mathrm{Fe}(\sim 40 \%)$. Third, water soluble organic carbon (WSOC) is removed from the sample and may be analysed separately. The WSOC contains a significant fraction of medium-mass organic matter, often referred to as humic-like substances, HULIS (Krivácsy et al., 2000). The term, originally coined for organic matter found in alkaline extracts of dust samples (Havers et al., 1998), is rather misleading. The mere fact that electrospray mass spectra of the extracted organic matter reveal a broad band of lines centred at about m/z 160 (Krivácsy et al., 2000) does not provide a justification for a wording that implies reasonably detailed knowledge of the composition of WSOC. Thorough electrospray mass spectrometric analyses of a variety of fulvic acids, the water soluble components of humic acids, revealed broad spectra extending from about $\mathrm{m} / \mathrm{z} 100$ to $\mathrm{m} / \mathrm{z} 500$ and beyond (Plancque et al., 2001). Similarly, time-of-flight secondary ion mass spectra of solidified fulvic acids were found to exhibit tails up to at least $\mathrm{m} / \mathrm{z} 3000$ (Szymczak et al., 2000). The proposed structure of fulvic acid molecules features a benezene ring substituted with carboxyl groups and alkyl chains (Plancque et al., 2001).

In a study related to this work, Novakov et al. (2000) examined the changes in the thermograms resulting from the removal of soluble matter in either acetone or water. A rather large (40 to $70 \%$ ) loss of $\mathrm{BC}$ was observed with the water treated samples. A similar loss was not observed after extraction with acetone. The dislodgment of $\mathrm{BC}$ particles in water was tentatively attributed to the rapid dissolution of sulfate. It is worth noting that aerosol matter was collected on filters residing on perforated disks with holes having a diameter of 1 to $2 \mathrm{~mm}$. Hence the sampled aerosol matter accumulated to form a large set of hillock. This special feature might have been responsible for the particularly pronounced dislodgment of BC particles. In fact, a similar BC removal was never observed with normal uniform deposits on 37 or $47 \mathrm{~mm}$ quartz filters (Novakov, 2005) ${ }^{1}$.

\section{Methods}

In this study aerosol matter was sampled using a 5-stage Berner-type impactor (Hauke $\mathrm{GmbH}$ ) operated at a flow rate of $80 \mathrm{l} / \mathrm{min}$. The nozzles and the corresponding aerosol deposits are arranged along a circle with a diameter of $50 \mathrm{~mm}$. Annular aluminium foils, $12 \mu \mathrm{m}$ thick, with inner and outer diameters of 32 and $70 \mathrm{~mm}$, respectively, served as impaction substrates. To avoid contamination problems during the subsequent analysis the foils were not greased. Sampling was carried out on the campus of GSF, located on the northern outskirts of Munich, during a $22.5 \mathrm{~h}$ period in May 2000.

The sampled aerosol deposits were treated as follows. The total mass of the aerosol deposits on each foil was first determined gravimetrically. Water-soluble matter was then removed by depositing the impaction foils face down in $10 \mathrm{ml}$ of deionised water for $1 \mathrm{~h}$. The concentration of inorganic ions was determined by ion chromatography (Wittmaack and Keck, 2004). After drying of the impaction foils, the mass of the residual water-insoluble deposits was also determined gravimetrically. The water extracts showed minor quantities of diesel soot particles dispersed in the solution. The estimated loss was well below $10 \%$. Small sections containing between eight spots in stage 1 and one spot in stage 4 were cut from the impaction foils for separate heat treatment and analysis (for stage assignment, number of nozzles, nozzle diameter, and aerodynamic cut diameter see Fig. 1a). Each section was heated only once in ambient air, to temperatures between 200 and $600^{\circ} \mathrm{C}$, for $1 \mathrm{~h}$. This procedure is somewhat reminiscent of the two-step protocol used by Cachier et al. (1989) and the constant heat-rate protocol of Novakov

\footnotetext{
${ }^{1}$ Novakov, T.: personal communication, 2005.
} 
et al. (2000), both groups applying an oxidative environment from the beginning of sample heating. According to Cachier (1989) heating in an oxidative gas prevents charring due to pyrolysis of organic matter, a problem routinely encountered during intial heat treatment in pure helium. If charring had occurred in the experiments of this study, the produced black carbon (BC) should become observable as a distinct change of the carbon signal, at the same or almost the same temperature as EC.

Prior to SEM analysis the samples were covered with a conducting layer of sputter deposited platinum (nominal thickness $3 \mathrm{~nm}$ ). SEM images were recorded using a model JSM-6300F scanning electron microscope (Jeol), equipped with a field emission electron gun operated at $5 \mathrm{kV}$. A model $6524 \mathrm{Si}(\mathrm{Li})$ detector (Link Analytical) served for acquiring energy dispersive X-ray (EDX) spectra. To achieve optimum sensitivity for light elements, the detector was operated with an open window. EDX analysis was usually carried out while scanning the electron beam over an area of $60 \times 42 \mu \mathrm{m}$. Occasionally small-area analysis $(4 \times 3 \mu \mathrm{m})$ was performed to determine the composition of individual mineral particles. For that purpose the beam energy was increased to $15 \mathrm{keV}$ (window closed).

\section{Results and discussion}

\subsection{Gross description of samples}

The size dependent differences between the aerosol deposits collected in the different impactor stages are illustrated in Fig. 1. The total mass after sampling ranged from 50 to $350 \mu \mathrm{g}$ per stage, the water insoluble mass from about 10 to $150 \mu \mathrm{g}$ (Fig. 1a). Different from stages 4 and 5, which contained a large amount of water insoluble mineral dust, the soluble fraction was typically $60 \%$ in stages $1-3$ (mostly ammonium sulphate and nitrate). This result is in accordance with recent studies on PM2.5 matter (Wittmaack and Keck, 2004). Assuming that the residual insoluble aerosol matter had a mean mass density of $2 \mathrm{~g} / \mathrm{cm}^{3}$ (Berner and Lrzer, 1980; Wittmaack, 2002a) and was uniformly distributed over an area equivalent of the respective nozzle area, the mean coverage per stage can be calculated in units of monolayers (ML), as shown in Fig. 1b (the thickness of one monolayer was set equal to the geometric mean aerodynamic diameter in the respective impactor stage). In stages 1 and 3 the deposits were found to be about five ML thick, even thicker in stage 2 (about $18 \mathrm{ML}$ ), but only $0.3 \mathrm{ML}$ in stage 4 . Accordingly, the nominal areas of deposition should to be densely covered in stages $1-3$, but only partially in stage 4 . However, due to enhanced deposition near the jet axis, described in detail recently (Wittmaack, 2002b), the local thickness in the centre of the deposit was larger, possibly by up to a factor of two. The SEM and EDX data presented below are in accordance with this estimate. The fractional coverage in stage 5

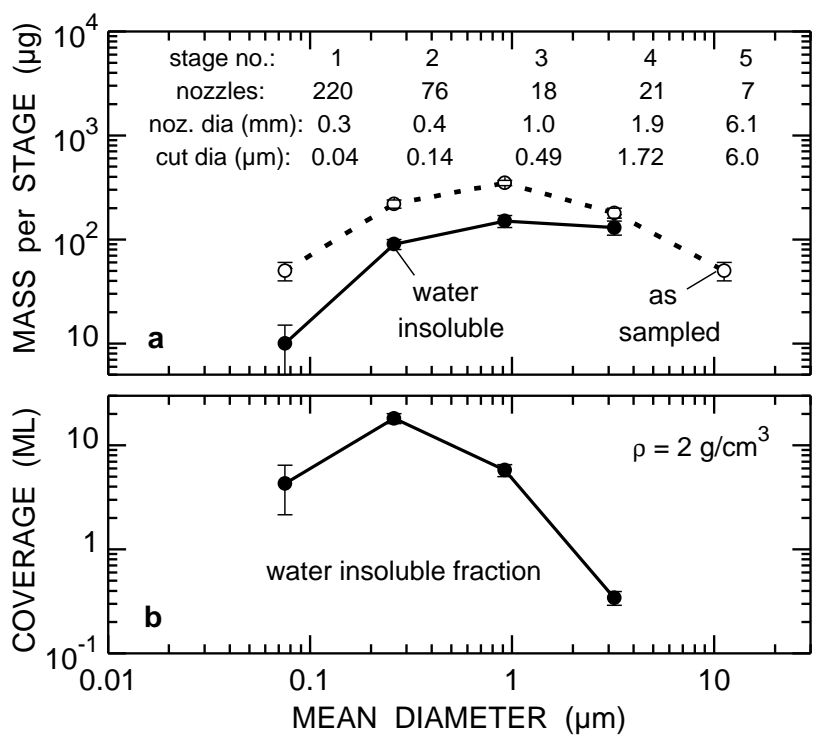

Fig. 1. Gross characterisation of the analysed aerosol samples in terms of (a) the mass per stage and (b) the mean number of layers in units of the mean particle diameter. The impactor specifications are listed in the top part of panel (a). For conversion of mass to mass concentration $\left(\mu \mathrm{g} / \mathrm{cm}^{3}\right)$, the data in panel (a) must be divided by the volume of sampled air, i.e., $102 \mathrm{~m}^{3}$.

was found to be even smaller than in stage 4 . Hence stage 5 was not included in the detailed analysis described below.

\subsection{SEM analysis}

Evidence for a significant concentration of diesel soot particles in the ambient air at the GSF sampling site has already been presented before (Wittmaack, 2004; Wittmaack et al., 2005). Figure 2 shows examples of these densely packed carbon nanoparticles near the centre of deposits in impactor stage 4 (panel a, unheated; referred to as room temperature, RT) and stage 3 (panel b, after heating to $300^{\circ} \mathrm{C}$; in what follows the term "after heating to" will be skipped for brevity, only the temperature of the heating cycle will be quoted). There is no detectable difference in the morphology of the nanoparticles for the RT and $300^{\circ} \mathrm{C}$ samples. In the stage $3 / 510^{\circ} \mathrm{C}$ sample (Fig. 2c), on the other hand, diesel soot particles are no longer detectable, i.e. they have been lost by combustion. As a results the much larger mineral particles become clearly observable. EDX analysis showed that these particles are composed mostly of $\mathrm{Si}, \mathrm{Fe}$, and $\mathrm{O}$, with additional contributions due to $\mathrm{K}, \mathrm{Ti}$ and $\mathrm{Ca}$.

A closer inspection of Fig. 2c shows some aggregated very small particles on the much larger mineral particles. The tiny particles, which could be misinterpreted as residual carbon nanoparticles, are actually some kind of ash presumably left behind as a result of the combustion of the diesel soot particles at $510^{\circ} \mathrm{C}$. Figure 3 illustrates the differences 

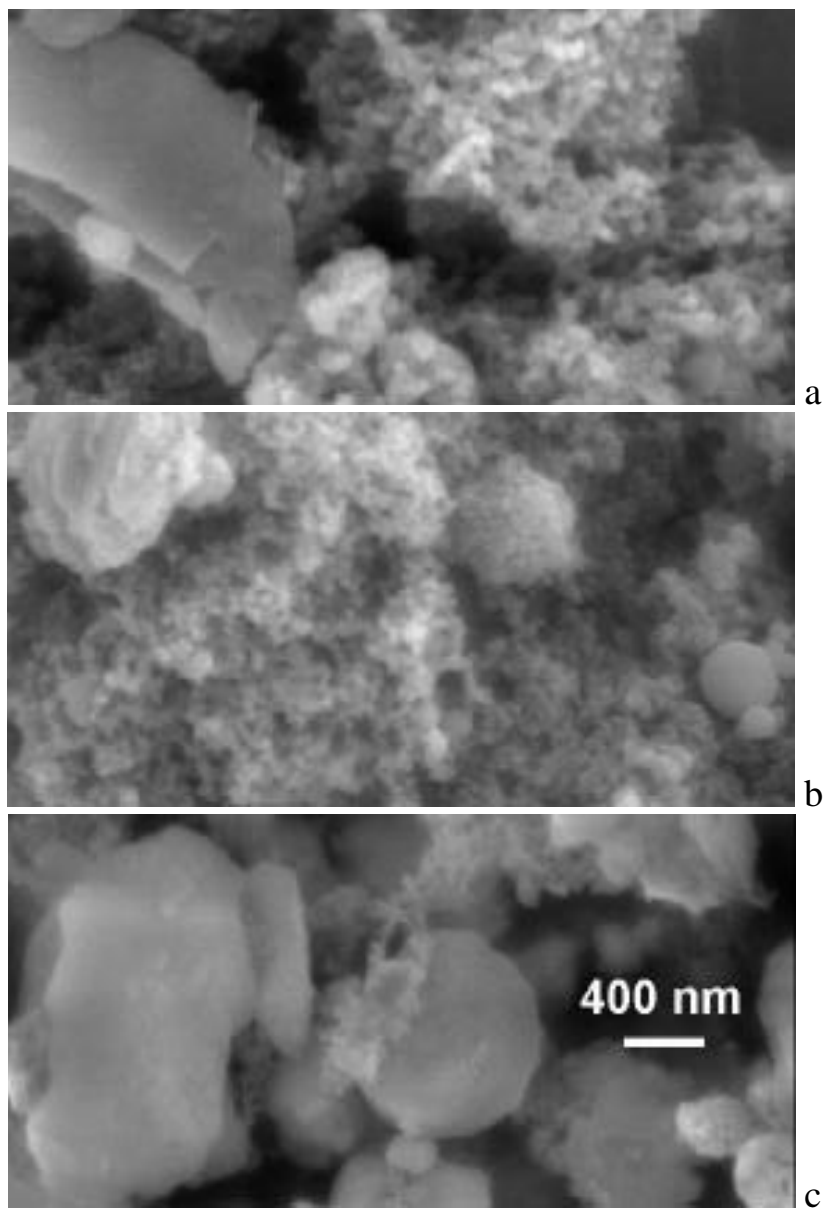

Fig. 2. SEM images showing diesel soot particles (a) in an asprepared sample (stage 4), (b) after heating to $300^{\circ} \mathrm{C}$ (stage 3 ) and (c) to $510^{\circ} \mathrm{C}$ (stage 3 ). The magnification is the same in all three panels.

in morphology of the two types of nanoparticles. Two highresolution images of diesel soot particles observed at RT outside the central area of aerosol deposition in stages 1 and 2 are presented in Figs. 3a and b, respectively. Similar chain aggregates have been described repeatedly (Bérubé et al., 1999; Wentzel et al., 2003; Van Gulijk et al., 2004; Wittmaack, 2004). The important aspect to note with reference to Figs. 3a and $b$ is that the individual aggregated particles feature distinctly different sizes, about $20 \mathrm{~nm}$ in panel a, but between 30 and $40 \mathrm{~nm}$ in panel b. Almost the same differences in the size of diesel soot particles have been reported recently (Wentzel et al., 2003), but a reason for the difference could not be provided. More work appears to be necessary to fully understand the growth mechanism of diesel soot particles. An emerging technique for advanced chemical characterisation of diesel soot is Raman microspectroscopy (Sadetzky et al., 2005).

For comparison, the residues of combustion in stage $2 / 600^{\circ} \mathrm{C}$ are shown in Fig. 3c. The individual particles in
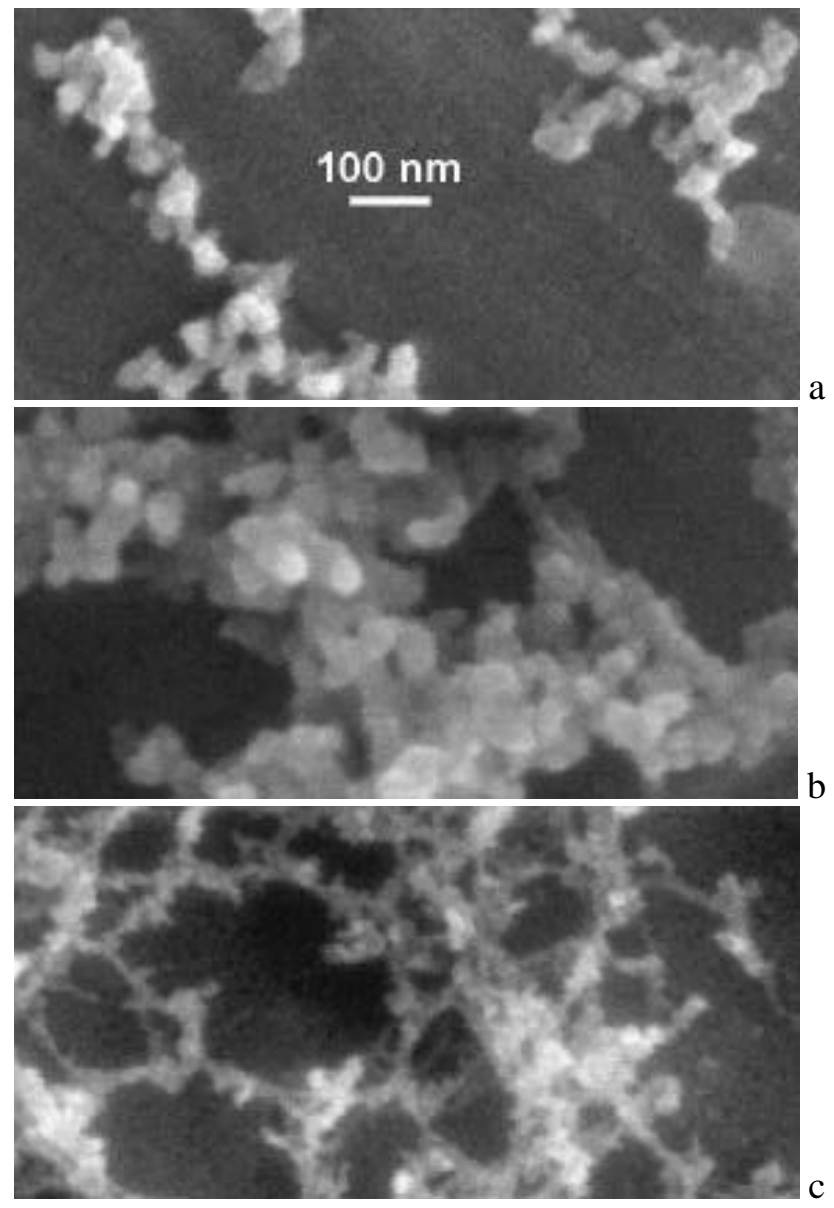

Fig. 3. High-resolution SEM images of diesel soot particles in asprepared samples, (a) stage 1 and (b) stage 2. (c) Residues left behind in stage 2 after sample heating to $600^{\circ} \mathrm{C}$. The magnification is the same in all three panels.

the aggregates have sizes less than $10 \mathrm{~nm}$. Owing to an estimated resolution in the SEM analysis of $2-5 \mathrm{~nm}$, the actual size could well be less than $5 \mathrm{~nm}$. Because of the very small amount of material contained in these particles, compositional analysis is extremely difficult, if not impossible. EDX analysis at $5 \mathrm{keV}$ showed very faint signals due to silicon, barely above the bremsstrahlung background. The particles could be the ash of diesel soot combustion. In fact, low concentrations of silicon in diesel soot have also been observed recently in transmission electron microscopy studies (Wentzel et al., 2003).

The temperature dependence of diesel soot combustion is evident from Fig. 4 which shows a compilation of lowresolution images of stage- 1 deposits. Increasing the temperature from (a) RT through (b) $200^{\circ} \mathrm{C}$ and (c) $400^{\circ} \mathrm{C}$ to (d) $440^{\circ} \mathrm{C}$ there is no detectable change, neither in the surface morphology nor in the density. At $480^{\circ} \mathrm{C}$ (e) there is a change in that individual carbon nanoparticle have become observable with better contrast. This change, which 

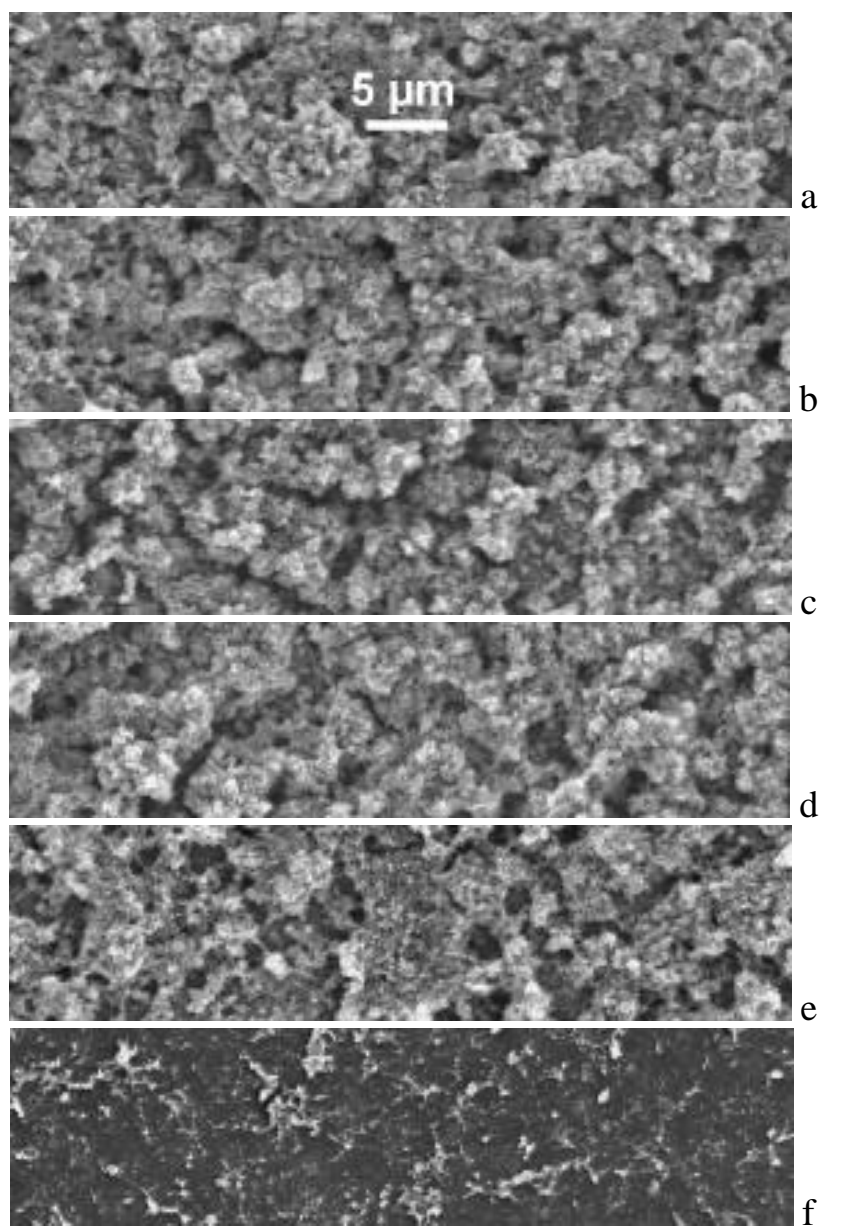

Fig. 4. Low-resolution SEM image of stage-1 deposits, (a) RT (asprepared), and after sample heating to different temperatures, (b) $200^{\circ} \mathrm{C}$, (c) $400^{\circ} \mathrm{C}$, (d) $440^{\circ} \mathrm{C}$, (e) $480^{\circ} \mathrm{C}$, and (f) $520^{\circ} \mathrm{C}$. The magnification is the same in all six panels.

has already been observed before with a different sample at $400^{\circ} \mathrm{C}$ (Wittmaack, 2004), could be due to desorption or combustion of OC containing matter (see Sect. 3.3). After a further increase in temperature to $520^{\circ} \mathrm{C}$ (f), the diesel soot particles have disappeared completely and only the residues discussed with reference to Fig. $3 \mathrm{c}$ are left behind. These findings imply that combustion of diesel soot EC in ambient air is characterised by a rather sharp threshold, somewhere between 490 and $510^{\circ} \mathrm{C}$.

The concentration of diesel soot particles was found to be high in stages 1 and 2, intermediate in stage 3 and comparatively low in stage 4 . Concurrent with the decrease in diesel soot concentration, the contribution due to mineral particles increased (note again that water soluble matter had been removed). The aerosol matter collected in stage 4 , however, exhibited a significant difference compared to stages $1-3$. Stage 4 contained a large amount of material of biological origin. A few examples are presented in Fig. 5. The small spherical objects seen in Fig. 5a are known as brochosomes produced
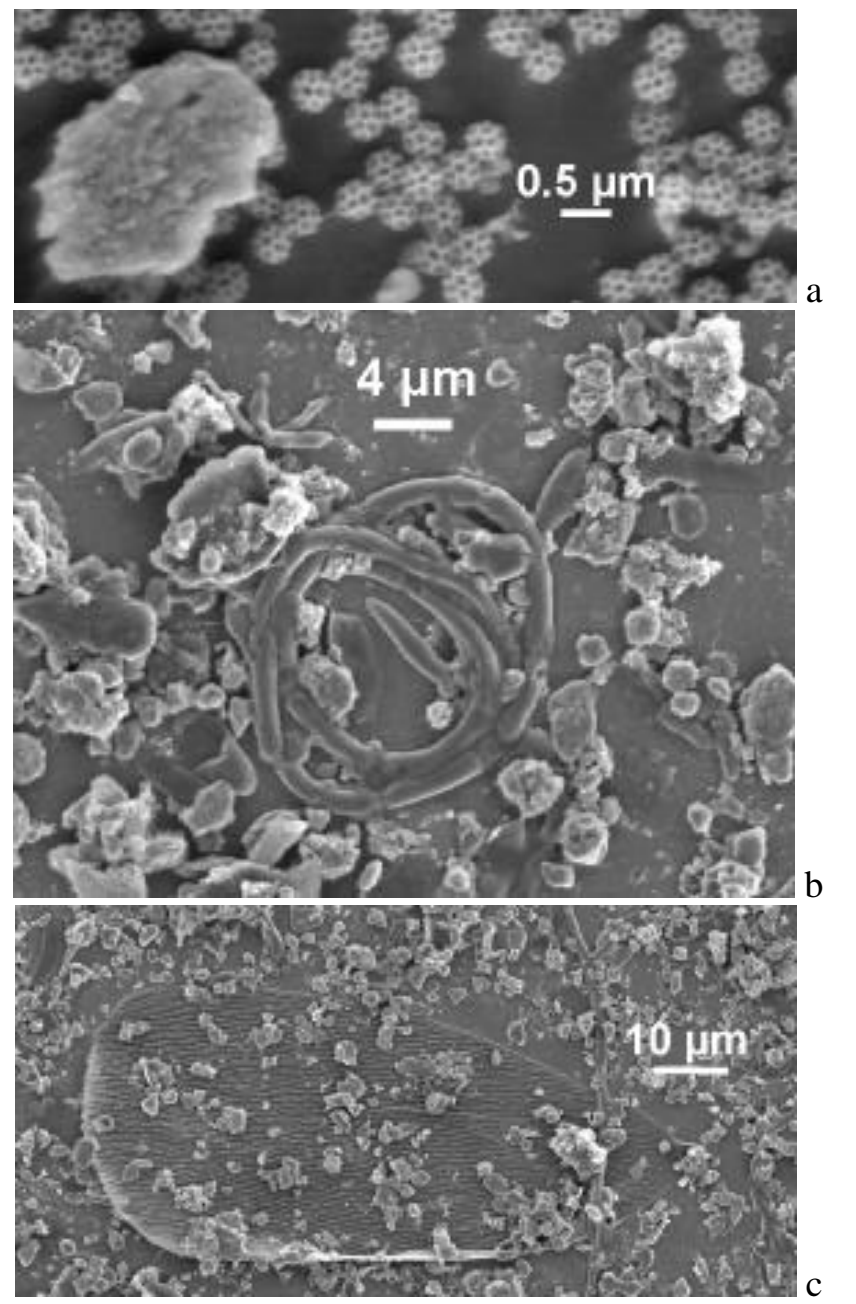

Fig. 5. Examples of bioaerosol matter observed in impactor stage 4, (a) brochosomes, (b) presumably a coiled hypha, (c) scale of an insect.

by insects. Recent studies revealed surprisingly high concentrations of these bioaerosol particles in ambient air during the warm season (Wittmaack, 2005; Wittmaack et al., 2005). The coiled object in Fig. $5 \mathrm{~b}$ could be a hypha, the product of a fungus; the huge, partially covered object in Fig. $5 \mathrm{c}$ is presumably the scale of an insect (Wittmaack et al., 2005).

Other examples of stage- 4 matter of biogenetic origin are depicted in Fig. 6a. The top section of the image shows some kind of waxy material. The lower section contains a stem-type bioaerosol. Combustion of this kind of object at $430^{\circ} \mathrm{C}$ presumably results in a product of the kind located along the centre of Fig. $6 \mathrm{~b}$. The interesting aspect here is that heating at $430^{\circ} \mathrm{C}$ did not cause complete but only partial combustion. In fact, residues due to partial combustion of bioaerosol matter were observed quite frequently, even after heating to temperatures as high as $600^{\circ} \mathrm{C}$. An example is shown in Fig. 6c. On the other hand, the waxy matter in Fig. 6a had disappeared completely at $300^{\circ} \mathrm{C}$. 


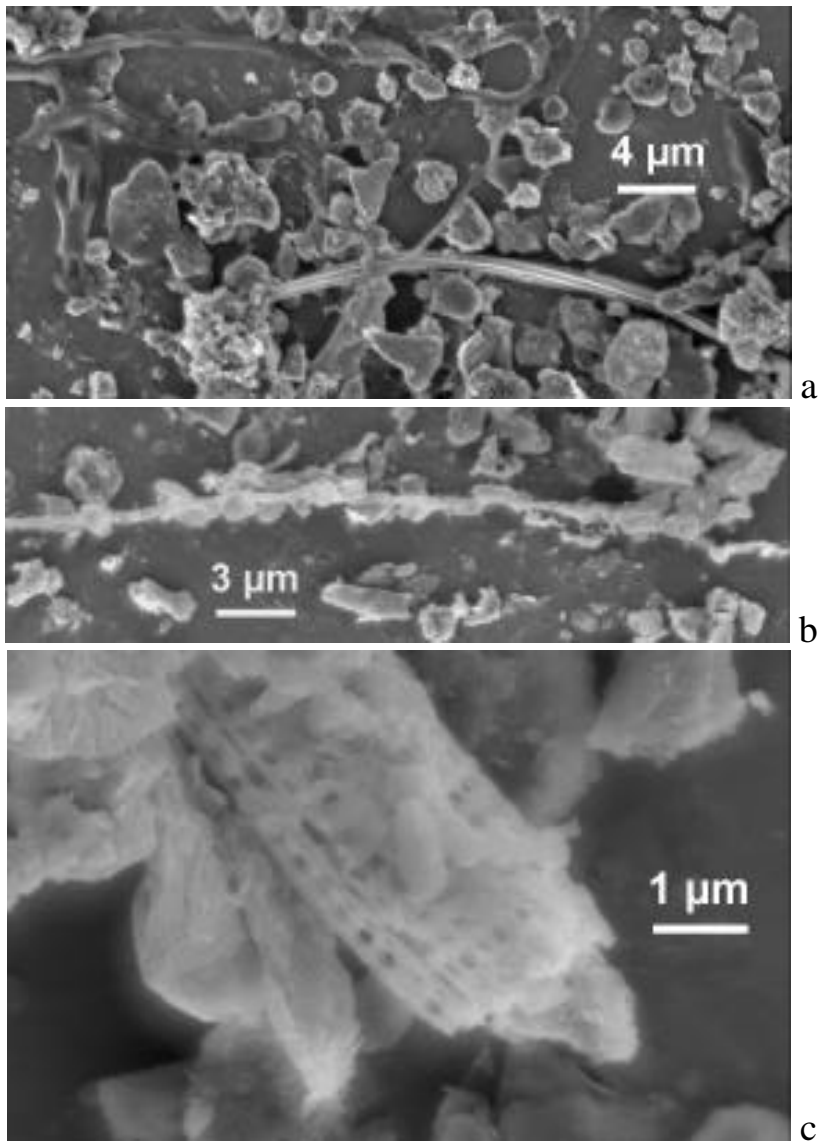

Fig. 6. Other types of bioaerosol matter observed in impactor stage 4, (a) RT (as-prepared), and after sample heating to (b) $430^{\circ} \mathrm{C}$ and (c) $600^{\circ} \mathrm{C}$.

The results presented above imply that water-insoluble OC matter of biogenetic origin will be observed in thermograms over a wide range of temperatures, from below $300^{\circ}$ to $600^{\circ} \mathrm{C}$ and more. Therefore, standard thermograms will be difficult to interpret, in particular when dealing with PM2.5 or even PM10 samples rather than with size fractionated matter. Owing to the variability of the bioaerosol fraction in aerosol matter, one would expect that PM samples collected during the warm season exhibit a more complex thermogram than samples collected during the cold season.

\subsection{EDX analysis}

The results obtained by SEM imaging were substantiated by EDX compositional analysis. Owing to the complex morphology of the deposits and the differences in sample thickness, evaluation of absolute concentrations did not seem to be justified. Hence the elemental signals are discussed only in terms of the background corrected peak X-ray yields.

As an example, Fig. 7 shows the temperature dependence of the yields of $\mathrm{C}, \mathrm{O}, \mathrm{Si}, \mathrm{Al}$ (all K-shell), and $\mathrm{Pt}$ (M-shell) for stage-1 aerosol deposits. In accordance with the SEM images

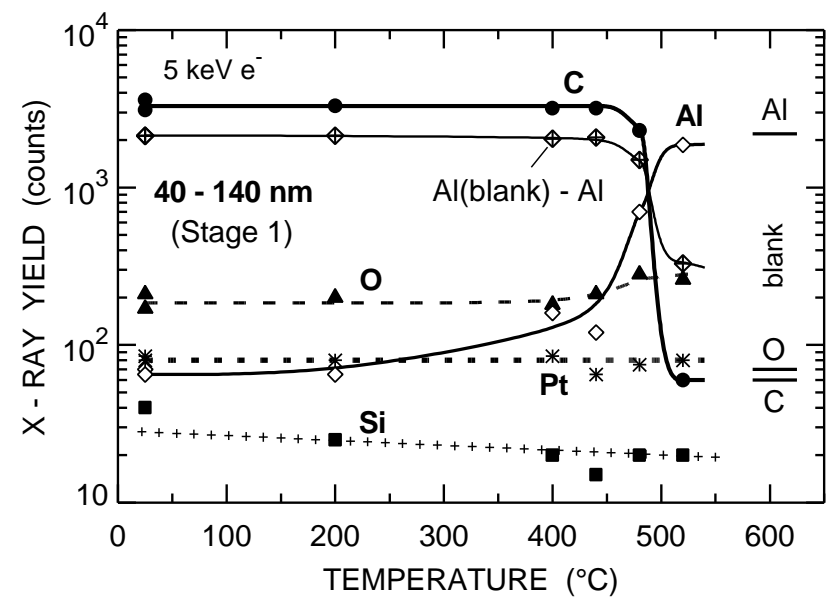

Fig. 7. Temperature dependence of X-ray signals for stage-1 aerosol matter. The signals due to the conducting Pt layer are shown for comparison. The horizontal bars to the left indicate the signals measured with a blank Al foil. The blank signal for Si was only $5 \pm 3$ counts. The comparatively large $\mathrm{Si}$-signal in an as-prepared section of the sample $\left(23^{\circ} \mathrm{C}\right)$ is probably due to a local contamination.

in Fig. 4, the $\mathrm{C}$ signal appears to remain essentially constant up to $440^{\circ} \mathrm{C}$, starts to decrease by about $30 \%$ at $480^{\circ} \mathrm{C}$ and, between 480 and $520^{\circ} \mathrm{C}$, drops rapidly to the level measured with a blank $\mathrm{Al}$ substrate. Concurrently the $\mathrm{Al}$ signal increases almost to the blank level. There is, however, a difference in that the $\mathrm{Al}$ signal exhibits an increase already at temperatures between about 300 to $400^{\circ} \mathrm{C}$. This change, which amounts to only about $5 \%$ of the blank level, is not detectable in the $\mathrm{C}$ data because relative changes of this magnitude are smaller than the statistical variations between different deposits of the same impactor stage. Plotting the results for $\mathrm{Al}$ in the form of an [Al(blank) - Al] yield difference (diamonds with central crosses), the close correlation between the $\mathrm{C}$ and $\mathrm{Al}$ data becomes fully evident. The signals measured for $\mathrm{O}$ and $\mathrm{Si}$ were clearly above the blank level (by a factor of three to four), indicating that the water-insoluble aerosol deposits in stage 1 contained some non-EC matter, presumably mineral oxides or OC (see below).

A comparison of the temperature dependence of the $\mathrm{C}$ and Al signals observed with the aerosol matter in the four different size ranges is presented in Figs. 8a and b. The corresponding data for $\mathrm{O}$ and $\mathrm{Si}$ are shown in Figs. 9a and b. Consider first the $\mathrm{Al}$ data in Fig. 8b. The important result is that only in the case of stage 2 (open triangles) the mean thickness of the deposits $\left(\sim 940 \mu \mathrm{g} / \mathrm{cm}^{2}\right)$ was so large so that the 5$\mathrm{keV}$ probing electron beam could not "see" the $\mathrm{Al}$ substrate. In stage $1\left(\sim 64 \mu \mathrm{g} / \mathrm{cm}^{2}\right)$, however, a small substrate signal was clearly detectable (solid circles). Hence small changes in the mass density of the deposits due to evaporation and/or combustion during heating to up to $400^{\circ} \mathrm{C}$ became detectable as an increase in the $\mathrm{Al}$ signal. Much more significant losses, on the order of $30 \%$, were deduced from the $\mathrm{C}$ and $\mathrm{Al}$ signals 


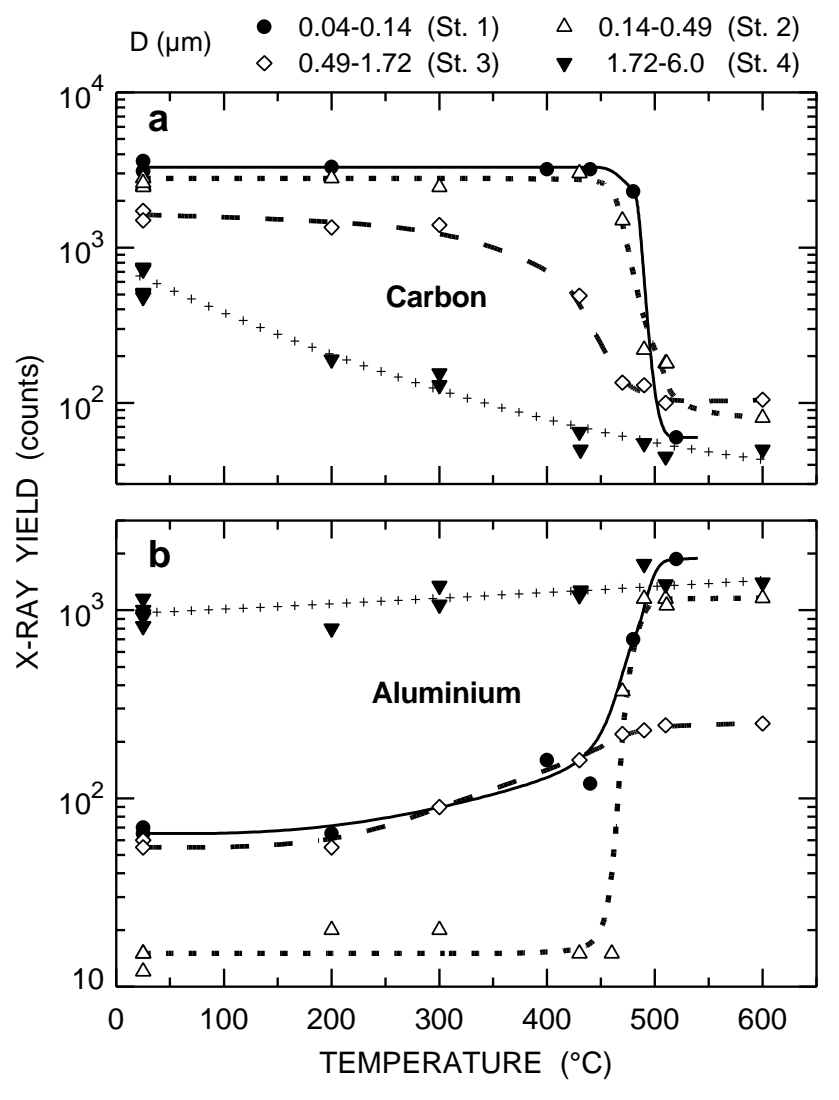

Fig. 8. Comparison of the temperature dependence of X-ray signals measured in the four different size ranges specified at the top, (a) carbon and (b) aluminium.

after heating to $480^{\circ} \mathrm{C}$. The tentative interpretation is that these losses are due to the combustion of water-insoluble OC contained in the aerosol sample. This OC is not evident in the form of particles identifiable by SEM. Instead the OC matter may be present in the form of a "hazy background" in the SEM images and possibly also as a thin layer on the diesel soot particles. Changes in morphology similar to those in Fig. 4 have previously been associated with the removal of adsorbed contaminants (Wittmaack, 2004).

The Al substrate signal was also detectable in stage 3 (open diamonds in Fig. 8b) even though the estimated thickness was quite large $\left(\sim 1060 \mu \mathrm{g} / \mathrm{cm}^{2}\right)$. This apparent discrepancy is probably due to the fact that, owing to the comparatively high concentration of mineral particles, the deposit contained a significant number of microscopic holes and clefts through which the beam could penetrate (Wittmaack et al., 2002). The high Al signal observed in stage 4, on the other hand, is due to the fact that the sample was only partially covered with various types of aerosol matter (see Figs. 5 and 6). The results for stages 3 and 4 indicate a significant loss of carbon at lower temperatures than in the case of stages 1 and 2. This difference is attribute to the increasing fraction of bioaerosol matter contained in the deposits.

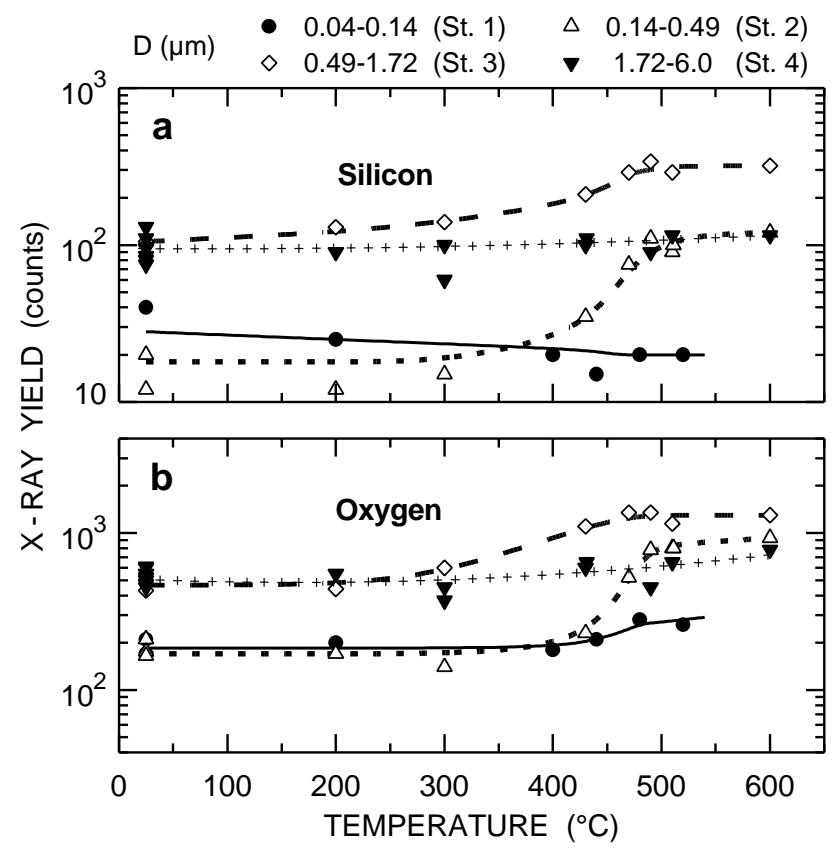

Fig. 9. The same as Fig. 8, but for (a) silicon and (b) oxygen.

In fact, a large loss of carbonaceous matter was observed in stage 4 already at $200^{\circ} \mathrm{C}$, see Fig. 8 a. Even though diesel soot particles could be found in stage 4 , the contribution to the total carbon content of the sample amounted to only a few percent so that the step-like combustion of $\mathrm{EC}$ around $500^{\circ} \mathrm{C}$ got lost in the background signal. This finding may also be considered as evidence that charring of particles in stage 4 (and 3) was negligible.

The results for $\mathrm{O}$ and $\mathrm{Si}$ in Fig. 9 complete the picture outlined above. The small signals observed in stage 1 suggest that the concentration of mineral dust was quite small. In stage 4, on the other hand, most of the mineral particles were not covered with carbonaceous matter (see Figs. 5 and 6) so that the $\mathrm{O}$ and $\mathrm{Si}$ signals reflecting their presence exhibited only a rather small increase due to combustion related losses. These losses, however, are clearly evident in stages 2 and 3, and the temperature dependence is in accordance with the results in Fig. 8. The relative changes are considerably smaller than for $\mathrm{Al}$, the reason being that the mineral particles producing the $\mathrm{O}$ and $\mathrm{Si}$ signals were presumably distributed fairly uniformly within the deposited layer so that a sizable fraction of these particles could be detected by the probing beam even before removal of carbonaceous matter by combustion.

\subsection{Comparison with previous work}

The present results call for a comparison with the results obtained previously using protocols that involve heating in an oxidative gas from the beginning of the carbon analysis. The thermograms reported by Novakov et al. (2000) show that a 
significant or event large amount of OC is removed at temperatures between 350 and $470^{\circ} \mathrm{C}$ or (even higher). The results in Fig. 8 substantiate this observation. Hence a combustion temperature of $340^{\circ} \mathrm{C}$, as used by Cachier et al. (1989), is much too low to fully separate BC from OC. Further support in this respect comes from the fact that, in the "carbon conference" round robin study (Schmid et al., 2001), the EC data reported by group \#7 (using the Cachier method) were always well above the low-concentration set of data reported by other groups. The "true" EC content of the analysed samples might come close to the very low concentrations reported by group \#8. The approach used by this group involved combustion in a helium/oxygen mixture at temperatures up to $340^{\circ} \mathrm{C}$, followed by sample heating to $650^{\circ} \mathrm{C}$ in (nominally) pure helium at $650^{\circ} \mathrm{C}$. All the carbon removed up to this step was ascribed to $\mathrm{OC}$. BC was subsequently determined by combustion at $650^{\circ} \mathrm{C}$ in helium/oxygen. The main uncertainty in this approach may be due to (i) the presence of catalytic components in the aerosol matter surrounding the carbonaceous substances and (ii) low-level oxygen impurities that could have contaminated the pure helium during the long-term (25-min) heating procedure.

The thermograms reported by the Berkeley group (Novakov et al., 2000; Kirchstetter et al., 2001) suggest that an appreciable amount of OC is released at the same temperature as $\mathrm{BC}$, i.e. between about 460 and $560^{\circ} \mathrm{C}$. Hence by way of fitting a Gaussian curve to the high-temperature end of the thermogram without accounting for an OC background one will overestimate the EC content. According to the results described here, EC in the form of diesel soot particles exhibits combustion within a narrow temperature range (30$40^{\circ} \mathrm{C}$ ), small compared to the half width of the nominal BC peak $\left(80^{\circ} \mathrm{C}\right)$ observed during heating at a rate of $20^{\circ} \mathrm{C} / \mathrm{min}$. The high rate may mask some of the structure that could become observable at significantly lower heating rates.

Probably the most important problem associated with previous attempts to distinguish between $\mathrm{OC}$ and $\mathrm{EC}$ in aerosol matter is due to sampling on filter, notably in the case of PM10 (Lavanchy et al., 1999; Mader et al., 2003). The complex mixture of inorganic compounds with carbonaceous matter in the form of nanoparticle combustion products, uncountable types of organic molecules and many different bioaerosols will result in very complex thermograms. The problem becomes evident from calibration experiments which showed, for example, that 11 to $17 \%$ of a humic acid test sample might be identified as EC (Lavanchy et al., 1999). Very severe positive OC artefacts, by as much as a factor of two, can occur in filter sampling due to the adsorption of ambient organic gases (Kirchstetter et al., 2001; Mader et al., 2003). Such problems will be significantly reduced or even fully avoided by impactor sampling. The other big advantage of using impactors is that different types of carbonaceous matter (e.g. nanoaparticles and bioaerosols) will become reasonably well separated so that thermograms should become less difficult to interpret.

\section{Conclusions}

This study has provided further evidence that SEM in combination with EDX is an indispensable tool for characterising ambient aerosol matter in terms of morphology, origin and combustion behaviour. To ease distinction between the OC and EC particles, initial removal of water soluble matter is highly advisable. Care needs to be taken to make sure that EC particles are not dislodged from the aerosol deposit to become suspended in the water. Analysis of the water-insoluble fraction of aerosol deposits collected in an impactor revealed very pronounced size dependent differences in composition. Carbonaceous matter was observed mostly in the form of diesel soot carbon nanoparticles (EC) and various types of material of biogenetic origin (OC). The diesel soot particles featured step-like combustion centred around $500^{\circ} \mathrm{C}$. Combined with gravimetric data, the SEM results suggest that the EC fraction in water-insoluble aerosol matter was very large (70\%) in the size range below $140 \mathrm{~nm}$ and large below $500 \mathrm{~nm}$. However, the estimated contribution to the total PM1.7 mass was small, i.e. only between 5 and $8 \%$. Bioaerosols and other OC matter not fully identified by SEM disappeared by evaporation and combustion over a comparatively wide range of temperatures, from below $200^{\circ} \mathrm{C}$ to $500^{\circ} \mathrm{C}$ or more. Some types of bioaerosol matter require combustion temperatures well above $600^{\circ} \mathrm{C}$. Carbon combustion signals due to these bioaerosols might missleadingly be attributed to EC.

Acknowledgements. Thanks are due to U. Heinzmann who provided access to the scanning electron microscope, to $\mathrm{H}$. Wehnes for skilfully taking the SEM images and the EDX spectra, and to J. Schnelle-Kreis for assistance with sampling.

Edited by: U. Pöschl

\section{References}

Berner, A. and Lürzer, C.: Mass size distributions of traffic aerosols at Vienna, J. Chem Phys., 84, 2079-2083, 1980.

Bérubé, K. A., Jones, T. P., Williamson, B. J., Winters, C., Morgan, A. J., and Richards, R. J.: Physicochemical characterisation of diesel exhaust particles: Factors for assessing biological activity, Atmos. Environ., 33, 1599-1614, 1999.

Cachier, H., Bremond, M. P., and Buat-Ménard, P.: Determination of atmospheric soot carbon with a simple thermal method, Tellus 41B, 379-390, 1989.

Cachier, H.: Carbonaceous Combustion Aerosols, in: Atmospheric Particles, edited by: Harrison, R. M. and Van Grieken, R., John Wiley and Sons, Chichester, Chapter 9, 1998.

Chow, J., Watson, J. G., Crow, D., Lowenthal, D. H., and Merrifield, T.: Comparison of IMPROVE and NIOSH carbon measurements, Aerosol Sci. Technol., 34, 23-34, 2001.

Havers, N., Burba, P., Lambert, J., and Klockow, D.: Spectroscopic characterisation of humic-like substances in airborne particulate matter, J. Atmos. Chem., 29, 45-54, 1998. 
Hitzenberger, R., Jennings, S. G., Larson, S. M., Dillner, A., Cachier, H., Galambos, Z., Rouc, A., and Spain, T. G.: Intercomparison of measurement methods for black carbon aerosol, Atmos. Environ., 33, 2823-2833, 1999.

Ishiguro, T., Takatori, Y., and Akihama, K.: Microstructure of diesel soot particles probed by electrom micrscopy: First observation of inner core and outer shell, Combustion and Flame, 108, 231-234, 1997.

Kirchstetter, T. W., Corrigan, C. E., and Novakov, T.: Laboratory and field investigation of the adsorption of gaseous organic compounds onto quartz filter, Atmos. Environ., 35, 1663-1671, 2001.

Krivácsy, Z., Kiss, G., Varga, B., Galambos, I., Sárvári, Z., Gelencsér, A., Molnár, Á., Fuzzi, S., Facchini, M. C., Zappoli, S., Andracchio, A., Alsberg, T., Hansson, H. C., and Persson, L.: Study of humic-like substances in fog and interstitial aerosol by size-exclusion chromatography and capillary electrophoresis, Atmos. Environ., 34, 4273-4281, 2000.

Lavanchy, V. M. H., Gäggeler, H. W., Nyeki, S., and Baltensperger, U.: Elemental carbon (EC) and black carbon (BC) measurements with a thermal method and an aethalometer at the high-alpine research station Jungfraujoch, Atmos. Environ., 33, 2759-2769, 1999.

Mader, B. T., Schauer, J. J., Seinfeld, J. H., Flagan, R. C., Yu, J. Z., Yang, H., Lim, H.-J., Turpin, B. J., Deminter, J. T., Heidemann, G., Bae, M. S., Quinn, P., Bates, T., Eatough, D. J., Huebert, B. J., Bertram, T., and Howell, S.: Sampling methods used for the collection of particle-phase organic and elemental carbon during ACE-Asia, Atmos. Eniviron., 37, 1435-1449, 2003.

Molnár, A., Mészáros, E., Hansson, H. C., Karlsson, H., Gelencsér, A., Kiss, G. Y., and Krivácsy, Z.: The importance of organic and elemental carbon in the fine atmospheric aerosol particles, Atmos. Environ., 33, 2745-2750, 1999.

Novakov, T. and Corrigan, C. E.: Thermal characterization of biomass smoke particles, Microchim. Acta, 119, 157-166, 1995.

Novakov, T., Bates, T. S., and Quinn, P. K.: Shipboard measurements of concentrations and properties of carbonaceous aerosols during ACE-2, Tellus 52B, 228-238, 2000.

Plancque, G., Amekraz, B., Moulin, V., Toulhat, P., and Moulin, C.: Molecular structure of fulvic acids by electrospray with quadrupole time-of-flight mass spectrometry, Rapid Commun. Mass Spectrom., 15, 827-835, 2001.

Putaud, J.-P., Raes, F., Van Dingenen, R., Brüggemann, E., Facchini, M.-C., Decesari, S., Fuzzi, S., Gehrig, R., Hüglin, C., Laj, P., Lorbeer, G., Maenhaut, W., Mihalopoulos, N., Müller, K., Querol, X., Rodriguez, S., Schneider, J., Spindler, G., ten Brink, H., Tørseth, K., and Wiedensohler, A.: A European aerosol phenomenology - 2: chemical characteristics of particulate matter at kerbside, urban, rural and background sites, Atmos. Environ., 38, 2579-2595, 2004.

Sadetzky, A., Muckenhuber, H., Grothe, H., Niessner, R., and Pöschl, U.: Raman microspectroscopy of soot and related carbonaceous materials: Spectral analysis and structural information, Carbon, 43, 1731-1742, 2005.
Schmid, H., Laskus, L., Abraham, H. J., Baltensperger, U., Lavanchy, V., Bizjak, M., Burba, P., Cachier, H., Crow, D., Chow, J., Gnauk, T., Even, A., ten Brink, H. M., Giesen, K.-P., Hitzenberger, R., Hueglin, C., Maenhaut, W., Pio, C., Carvalho, A., Putaud, J.-P., Toom-Sauntry, D., and Puxbaum, H.: Results of the "carbon conference" international aerosol carbon round robin test stage I, Atmos. Environ., 35, 2111-2121, 2001.

Szymczak, W., Wolf, M., and Wittmaack, K.: Characteristation of fulvic acids and glycyrrhizic acid by time-of-flight secondary ion mass spectrometry, Acta Hydrochim. Hydrobiol., 28, 350-358, 2000.

Ten Brink, H., Maenhaut, W., Hitzenberger, R., Gnauk, T., Spindler, G., Even, A., Chi, X., Bauer, H., Puxbaum, H., Putaud, J.-P., Tursic, J., and Berner, A.: Intercomp2000: the comparability of methods in use in Europe for measuring the carbon content of aerosols, Atmos. Environ., 38, 6507-6519, 2004.

Van Gulijk, C., Marijnissen, J. C. M., Makkee, M., Moulijn, J. A., and Schmidt-Ott, A. : Measuring diesel soot with a scanning mobility particles sizer and an electrical low-pressure impactor: performance assessment with a model for fractal-like agglomerates, J. Aerosol Sci. 35, 633-655, 2004.

Wentzel, M., Gorzawski, H., Naumann, K.-H., Saathoff, H., and Weinbruch, S.: Transmission electron microscopical and aerosol dynamical characterization of soot aerosols, J. Aerosol. Sci., 34, 1347-1370, 2003.

Wittmaack, K.: Advanced evaluation of size-differential distributions of aerosol particles, J. Aerosol Sci., 33, 1009-1025, 2002a.

Wittmaack, K.: Impact and growth phenomena observed with submicrometer atmospheric aerosol particles collected on polished silicon at low coverage, Atmos. Environ. 36, 3963-3971, 2002b.

Wittmaack, K., Menzel, N., Wehnes, H., and Heinzmann, U.: Phase separation and regrowth of aerosol matter collected after size fractionation in an impactor, Atmos. Environ., 36, 5877-5886, 2002.

Wittmaack, K. and Keck, L.: Thermodesorption of aerosol matter on multiple filters of different materials for a more detailed evaluation of sampling artefacts, Atmos. Environ., 38, 5205-5215, 2003.

Wittmaack, K.: Characterization of carbon nanoparticles in ambient aerosols by electron microscopy and model calculations, J. Air Waste Manag. Assoc., 54, 1091-1098, 2004.

Wittmaack, K.: Brochosomes produced by leafhoppers - a widely unknown, yet highly abundant species of bioaerosols in ambient air, Atmos. Environ., 39, 1173-1180, 2005.

Wittmaack, K., Wehnes, H., Heinzmann, U., and Agerer, R.: An overview on bioaerosols viewed by scanning electron microscopy, Sci. Total Environ., 346, 244-255, 2005. 